\title{
Policy Uncertainty and Economic Reforms in a Monetary Union
}

\author{
Carsten Hefeker ${ }^{*}$ \\ University of Siegen, HWWI Hamburg, and CESifo Munich ${ }^{* *}$
}

January 2008

\begin{abstract}
:
The paper analyzes the relation between monetary uncertainty and government incentives to implement economic reforms that reduce structural distortions and make economies more flexible. It is shown that uncertainty about the central bank's reaction function leads to more reforms. I relate this result to the debate about central bank setup in a larger monetary union.
\end{abstract}

JEL classification: D 72, E 52, E 58, F 33.

Keywords: Transparency of Monetary Policy, European Monetary Union, Labor Market Regulation.

\footnotetext{
* I thank participants in seminars in Aachen, Berlin and Munich, especially Helge Berger, Bernd Hayo and Ken Kletzer, for helpful comments.

** Department of Economics, University of Siegen, Hoelderlinstrasse 3, 57068 Siegen, Germany, Tel: +49-271-740.3184, Fax: +49-271-740.4042, carsten.hefeker@uni-siegen.de.
} 


\section{Introduction}

Faced with the enlargement of the monetary union to new member states, it is often argued that a successful integration of new members requires their nominal and real convergence to present member states. A monetary union with members too diverse will make the task of the European Central Bank, the ECB, more difficult and member states more vulnerable to shocks because monetary policy cannot react to national idiosyncratic shocks. Therefore, individual economies must become more flexible in response to economic shocks. ${ }^{1}$ Does monetary union make governments more or less willing to implement structural reforms?

Distinguishing between structural distortions and measures that increase the flexibility of the economy, I show that the introduction of a monetary union per se will tend to have different effects on member countries. All governments have an incentive to make their economies more flexible because they realize the common central bank can no longer react to idiosyncratic economic shocks. To counter this effect, economies must become more flexible, and this effect is strongest for smaller economies. The response of governments to monetary union with respect to structural reforms, however, is very different. Like earlier literature, I find that incentives for governments to reduce structural distortions in a monetary union are lowered. This is particularly the case for the more distorted economies whereas the less distorted economies implement more reforms. Monetary union is thus likely to lead to a further polarization between more and less distorted economies, making the conduct of monetary policy presumably even more difficult.

Monetary union, and the extension of it, also implies that economic agents and governments are faced with a new monetary authority as European Monetary Union (EMU) also implies that more national policy makers influence monetary policy. This is likely to

\footnotetext{
${ }^{1}$ This is, of course, the perspective of the optimum currency area literature, looking for alternative adjustment mechanisms when giving up national monetary policy.
} 
raise uncertainty about how a larger ECB board is likely to set policy. Allowing for uncertainty about the central bank's reaction function, it can be shown that this uncertainty increases the incentives for governments to implement more reforms, thus creating a so far overlooked relation between structural policies and monetary policy uncertainty. If governments can no longer rely on the central bank’s response to economic shocks and structural problems, they are pushed to provide more reform efforts themselves. Thus, while there are many good reasons for increasing central bank transparency, there is also a case for deliberately keeping some uncertainty about the central bank’s reaction function. ${ }^{2}$ Besides deliberately increasing opaqueness in a larger monetary union, there is another way to ensure some degree of uncertainty in a monetary union.

Applied to the extension of EMU, it is likely that a larger monetary union will, at least initially, be accompanied by an increase in uncertainty about the larger central bank’s reaction. Thus, the extension of the monetary union can, by creating more uncertainty, make governments more reform minded. Because uncertainty is presumably a function of the political weights of different countries, the results have also implications for the discussion about the ECB's structure. Current plans of centralizing the decision making power and reducing the number of policy makers in the ECB council by increasing a system of rotation of voting rights might thus be detrimental to reform incentives in a larger monetary union because they reduce uncertainty.

The paper is related to several strings in the literature. First, Calmfors (2001) and Sibert and Sutherland (2000) argued that monetary union will lead countries to being less reform willing because monetary policy and economic reforms are partial substitutes. The more reforms there are, the higher is output (or the lower is unemployment) and the less reason

\footnotetext{
2 The concept of transparency used here refers to "preference” uncertainty. For a recent discussion, see Hughes Hallett and Libich (2006).
} 
there is for active monetary policy. Inflation-averse governments thus have an incentive to deregulate in order to keep inflation low. In a monetary union the inflationary response to distortions in a single country is lower and therefore national governments run a more distionary policy without fearing inflation. By allowing for asymmetries between countries, I find instead that this not necessarily true for countries that enter a monetary union together with countries that are more distorted than they are themselves. In order to avoid an increase in inflation less distorted countries even increase their reforms so that there is a further polarization concerning the level of distortions (Hefeker 2005).

Secondly, I draw on is the huge literature on the influence of monetary policy uncertainty (Brainard 1967, Söderström 2002). Most of that literature deals with the consequences of uncertainty on the central bank's policy, showing that monetary authorities tend to be more careful if faced with parameter uncertainty, such as the transmission of monetary policy. My focus is how uncertainty about the central bank’s behavior will influence domestic agents. This issue has been explored in the literature on central bank transparency (see Eijffinger and Hoeberichts 2000, Winkler 2000, Geraats 2002, Carpenter 2004 for surveys). The question whether transparency is beneficial is usually analyzed in relation with the private sector, where several authors have pointed out that some degree of opaqueness and “creative ambiguity” can be beneficial for the economy (Cukierman and Meltzer 1986). Whereas earlier literature has focused on the influence of uncertainty on wage setters (Sorensen 1991, Grüner 2002), I analyze how governments react to such uncertainty, and find that more uncertainty leads governments to reduce structural distortions and to make the economy more flexible.

Finally, I relate to is the literature on the design of the common central bank. Most authors argue that because of efficiency considerations it is highly unlikely that an even larger ECB council will be able to make efficient and speedy policy decisions. Moreover, it is often 
argued that it can be expected that national representatives vote with a national perspectives (Baldwin et al. 2002, Berger 2006, Meade and Sheets 2002, Ullrich 2004). This implies that new member states will distort the ECB's decision, given that many of these countries are economically small but politically overrepresented (Berger 2006). Therefore, they might unduly influence the common central bank’s policy and lead to an inefficient policy from a European wide perspective. In contrast to that literature, I find there could also be a positive effect if enlargement creates more uncertainty. ${ }^{3}$

The paper is structured as follows. Section 2 explores the relation between economic reforms and uncertainty for a closed economy. Sections 3 and 4 discuss monetary union, and section 5 concludes.

\section{Policy Choices in the Closed Economy}

\subsection{The Model}

This section develops the underlying model and describes the interaction between a domestic government and a national central bank. Against this benchmark the case of monetary union will be compared. The following model is based on Sibert and Sutherland (2001).

Output $\mathrm{y}_{\mathrm{i}}$ is a positive function of surprise inflation $\pi_{\mathrm{i}}-\pi_{\mathrm{i}}^{\mathrm{e}}$ where $\pi_{\mathrm{i}}^{\mathrm{e}}$ is the subjective expected rate of inflation of the private sector. Output is decreasing in structural distortions $\tau_{\mathrm{i}}$, such as distortionary taxation, the presence of monopolies, tariff protection, or the impact of labor unions that lower output. ${ }^{4}$ Moreover, the economy may be hit by exogenous shocks $\varepsilon_{\mathrm{i}}$, with $\varepsilon_{\mathrm{i}} \sim \mathrm{N}\left(0, \sigma_{\varepsilon}^{2}\right)$, whose effect on output is given as $\mathrm{g}_{\mathrm{i}}=\gamma_{\mathrm{i}} \varepsilon_{\mathrm{i}}$. Making the economy more flexible by reducing labor and product market regulation can help the economy to adjust

\footnotetext{
${ }^{3}$ Another positive effect of a larger decision making body could be that more information is processed, thus allowing for better decisions (for a survey of these arguments, see Gerling et al. 2005).

${ }^{4} \tau_{\mathrm{i}}$ should be thought of as a vector of different policy measures and not one single policy.
} 
more quickly and thus cushion part of the shock. ${ }^{5}$ The lower the level of such regulations $\gamma_{\mathrm{i}}$, the lower will be the impact of exogenous developments and shocks. We hence have

$$
\mathrm{y}_{\mathrm{i}}=\left(\pi_{\mathrm{i}}-\pi_{\mathrm{i}}^{\mathrm{e}}\right)-\tau_{\mathrm{i}}-\mathrm{g}_{\mathrm{i}}
$$

Clearly, the first best situation would be reached if $\gamma_{\mathrm{i}}$ and $\tau_{\mathrm{i}}$ could be reduced to zero. However, it is assumed that the economy is starting out with given levels of distortions, $\bar{\gamma}_{\mathrm{i}}$ and $\bar{\tau}_{\mathrm{i}}$ and that deregulation is politically costly for the government. Abolishing labor market regulation might lead to protests, reducing structural distortions might prompt firms to threat a loss of jobs, and the reduction of taxes might imply the government is no longer able to finance pet projects. More regulation instead might lead to protests by employers and scare away foreign investors. Therefore, changes to the given level of $\bar{\gamma}_{i}$ and $\bar{\tau}_{\mathrm{i}}$ risk alienating one or several interest groups. As in Sibert and Sutherland (2001), I assume the political costs are increasing in deviations of $\gamma_{\mathrm{i}}$ and $\tau_{\mathrm{i}}$ from $\bar{\gamma}_{\mathrm{i}}$ and $\bar{\tau}_{\mathrm{i}}: \mathrm{C}_{\mathrm{i}}^{\tau}=\phi_{\tau}\left(\tau_{\mathrm{i}}-\bar{\tau}_{\mathrm{i}}\right)^{2}$ and $\mathrm{C}_{\mathrm{i}}^{\gamma}=\phi_{\gamma}\left(\gamma_{\mathrm{i}}-\bar{\gamma}_{\mathrm{i}}\right)^{2}$. The relative loss of government from these policy measures are given as $\phi_{\gamma}$ and $\phi_{\tau}$ respectively. For simplicity, I assume that utility parameters are equal for all governments. This is not necessarily a very realistic assumption but helps to focus on the economics of the model by abstracting from the influence of preferences.

Apart from wishing to minimize the political costs of reforms, the government aims to keep inflation close to zero and to avoid deviations from its natural level (whose log is normalized to zero). Its loss function is

\footnotetext{
${ }^{5}$ On the possible relations between the two types of reforms, see Berger and Danninger (2006).
} 


$$
\mathrm{E}\left[\mathrm{L}_{\mathrm{i}}\right]=\mathrm{E}\left[\pi_{\mathrm{i}}^{2}+\lambda \mathrm{y}_{\mathrm{i}}^{2}+\mathrm{C}_{\mathrm{i}}^{\tau}+\mathrm{C}_{\mathrm{i}}^{\gamma}\right]
$$

The objective function of the monetary authority is akin to the government's preferences but without the losses stemming from economic reform. Independent central banks are not elected into office, much less exposed to public resistance against policies and unlikely to be made responsible for economic reforms. Thus, the central bank is only concerned with the output gap and inflation. Another difference is that the preference parameter $\lambda_{\mathrm{i}}$ of the national central bank might differ from that of the government. The national monetary authority minimizes

$$
\mathrm{V}_{\mathrm{i}}=\pi_{\mathrm{i}}^{2}+\lambda_{\mathrm{i}} \mathrm{y}_{\mathrm{i}}^{2}
$$

I assume that the central bank sets its policy when possible uncertainties have been resolved. This reflects the standard timing in this type of model where it is usually assumed that the central bank sets its policy after stochastic shocks have realized, but where government and private sector react before uncertainties have been dissolved. The formal time structure is thus: (i) the government sets the levels of regulation $\gamma_{\mathrm{i}}$ and $\tau_{\mathrm{i}}$, (ii) the private sector forms its rational expectations about inflation $\pi_{\mathrm{i}}^{\mathrm{e}}$ based on the policy choices of the government, (iii) the shock $\varepsilon_{\mathrm{i}}$ is realized, (iv) the central bank sets inflation $\pi_{\mathrm{i}}$. The game structure is Stackelberg. The government is the Stackelberg leader taking into account how the central bank is likely to react to its policy choices. The private sector plays Nash against the government and the central bank. This reflects the idea that monetary policy follows after reform policies have been determined and that monetary policy can (to some degree) be foreseen by the government. 


\subsection{Uncertainty and Reforms}

The model is solved by backward induction. The central bank's reaction is derived first.

Optimization of the monetary authority's loss function with respect to inflation yields:

$$
\pi_{\mathrm{i}}=\theta_{\mathrm{i}}\left(\pi_{\mathrm{i}}^{\mathrm{e}}+\tau_{\mathrm{i}}+\gamma_{\mathrm{i}} \varepsilon_{\mathrm{i}}\right)
$$

$\theta_{\mathrm{i}}=\lambda_{\mathrm{i}} /\left(1+\lambda_{\mathrm{i}}\right)$ is the reaction parameter of the central bank which is obviously increasing in the relative weight it puts on stabilizing output $\lambda_{\mathrm{i}}$. Depending on the transparency of a single central bank, and especially if the central bank is run by a collegiate body, it could be that the central bank's reaction is not perfectly predictable by the private sector. The private sector will certainly form expectations about how the central bank reacts to economic developments, such as commodity price shocks, fiscal policy changes or wages, but the central bank's reaction will, in general, not be perfectly predictable. ${ }^{6}$ This uncertainty is likely to be larger the larger is the governing body and if new persons enter the central bank's decision making structure. The extension of the monetary union is a case where the central bank’s reaction function will be more uncertain than it is before enlargement. In terms of the model, this is represented by the fact that $\theta_{\mathrm{i}}$ can be stochastic. I assume $\theta_{\mathrm{i}} \sim \mathrm{N}\left(\theta, \sigma_{\theta}^{2}\right)$ if $\theta_{\mathrm{i}}$ is stochastic and hence $\sigma_{\theta}^{2}=0$ for a fully predictable central bank. ${ }^{7}$

\footnotetext{
${ }^{6}$ In fact, the standard assumption that the central bank's reaction can be predicted accurately might be a less realistic case than the assumption that there is some noise in the central bank's reaction.

${ }^{7}$ Thus uncertainty refers to the central bank’s preferences, as in Canzoneri (1985) and Cukierman and Meltzer (1986). An alternative way to model non-transparency is a nonobservable employment target or control errors (see Faust and Svensson 2001, 2002, Jensen 2002).
} 
Since government and private sector determine their action simultaneously, I consider next the government. The government optimizes its structural reforms and the ability of the economy to digest shocks by taking the expected reaction of the central bank into account.

The level of structural distortions remaining after reforms is

$$
\tau_{\mathrm{i}}=\frac{\phi_{\tau} \bar{\tau}_{\mathrm{i}}-\left(\lambda(1-\theta)^{2}+\Theta\right) \pi_{\mathrm{i}}^{\mathrm{e}}}{\phi_{\tau}+\left(\lambda(1-\theta)^{2}+\Theta\right)},
$$

where $\Theta=\theta^{2}+(1+\lambda) \sigma_{\theta}^{2}$ with $\mathrm{E}\left[\lambda_{\mathrm{i}}\right]=\lambda$ and $\mathrm{E}\left[\theta_{\mathrm{i}}\right]=\theta$.

The level of distortions set by the government is obviously higher the higher are initial distortions $\bar{\tau}_{\mathrm{i}}$ and government aversion to reforms $\phi_{\tau}$. It is decreasing in expected inflation because expected inflation pushes up actual inflation. In order to keep inflation to a moderate level, the government reacts to higher expected inflation with more reforms. The more uncertain is the reaction of the central bank (captured by $\Theta$ ), the more cautious is the government and the more reforms are implemented.

The amount of rigidity, remaining after reforms, is given as

$$
\gamma_{i}=\frac{\phi_{\gamma} \bar{\gamma}_{i}}{\phi_{\gamma}+\left(\lambda(1-\theta)^{2}+\Theta\right) \sigma_{\varepsilon}^{2}}
$$

It is increasing in the initial level of rigidity $\bar{\gamma}_{\mathrm{i}}$ and the aversion against flexibility $\phi_{\gamma}$ and decreasing in the variability of the economic shock $\varepsilon_{i}$, reflecting the fact that the government will make the economy more flexible if the variability of economic shocks is high. The uncertainty about the central bank's reaction and the variability of economic shocks reinforce each other. 
Assuming rational expectations, the expectations of the private sector are

$$
\pi_{\mathrm{i}}^{\mathrm{e}}=\mathrm{E}\left[\pi_{\mathrm{i}}\right]=\frac{\theta \phi_{\tau} \bar{\tau}_{\mathrm{i}}}{(1-\theta) \phi_{\tau}+\left(\lambda(1-\theta)^{2}+\Theta\right)}
$$

In contrast to the standard argument that expected inflation is falling in the central bank’s transparency (van der Cruijsen and Demertzis 2005), I find that expected inflation is decreasing in uncertainty. The simple reason is that uncertainty is reform increasing which leads the private to expect a less active monetary policy.

With these expectations, the amount of structural reforms in equilibrium is

$$
\tau_{\mathrm{i}}=\frac{(1-\theta) \phi_{\tau} \bar{\tau}_{\mathrm{i}}}{(1-\theta) \phi_{\tau}+\left(\lambda(1-\theta)^{2}+\Theta\right)} .
$$

Both types of distortions are thus decreasing in the amount of uncertainty about the central bank's reaction parameter to economic developments. The higher is the uncertainty the more the government will attempt to make the economy less vulnerable to shocks and to lower structural distortions in the economy. Thus, uncertainty is beneficial for inflation and output because the government's action have a direct positive impact on economic performance and an improvement in the economic performance reduces incentives to use monetary policy to boost output. Moreover, a more flexible economy requires less active monetary policy in response to shocks.

The rate of inflation will therefore result as 


$$
\pi_{\mathrm{i}}=\theta_{\mathrm{i}}\left(\frac{\phi_{\tau} \bar{\tau}_{\mathrm{i}}}{(1-\theta) \phi_{\tau}+\left(\lambda(1-\theta)^{2}+\Theta\right)}+\frac{\phi_{\gamma} \bar{\gamma}_{\mathrm{i}}}{\phi_{\gamma}+\left(\lambda(1-\theta)^{2}+\Theta\right) \sigma_{\varepsilon}^{2}} \varepsilon_{\mathrm{i}}\right) .
$$

\section{Policy Choices in the Monetary Union}

Having established the case of a single economy and the interaction between uncertainty and economic reforms, the question is how this is transformed in a monetary union. As argued above, uncertainty concerning the reaction function of the central bank is arguably more relevant in the case of the EMU, and particular so with the prospect of enlargement. There are at present 15 national representatives of member states and a board comprising additional six members. Extending this body to additional members will make decision making in the EMU more cumbersome and presumably less predictable than today. Extension means that new members will be added whose preferences are mostly unknown and who might shift the policy stance of the ECB. The interaction of a larger group of individuals in collective decision making might lead to an outcome that is different from what the smaller ECB council had decided. ${ }^{8}$ Especially in the initial years it is thus likely that the larger central bank council will create more uncertainty than before. Given that markets need some time to assess the preferences of policymakers (which has also happened with the initial group of monetary policymakers in the ECB, see Goldberg and Klein 2005), they might expect new members will bring different preferences to the ECB board. Even if markets expect that new members have similar preferences to older members, $E\left[\lambda_{2}\right]=\lambda_{1}=\lambda$, there might be some variance around this expected value at least for an initial period.

Moreover, it is likely that uncertainty will be larger if the voting power of the new members is large. First, the larger the relative size of the newcomers in respect to the older

\footnotetext{
${ }^{8}$ Goldberg and Klein (2005) show that the perception of the ECB's reaction parameter has changed over time as markets developed a view of the ECB's characteristics and the relative weight it assigns to different objectives.
} 
members, the higher their relative influence. This is obvious if monetary policy is a weighted average of individually preferred policies, but also if monetary policy is determined by the median voter, different preferences of newcomers shift the median's position (Hefeker 2003). Finally, even if monetary policy is set by consensus, as the ECB claims it is, new members will have more influence the larger is their group. Therefore the amount of uncertainty created is arguably a positive function of the relative voting weight of the new members. ${ }^{9}$

To keep matters simple, I consider a monetary union built of two countries only. Let country 1 represent the current members of the EMU and country 2 represent the new members. I assume $\mathrm{s}_{1}+\mathrm{s}_{2}=1$ and $\mathrm{z}_{1}+\mathrm{z}_{2}=1$ where $\mathrm{s}_{\mathrm{i}}$ is the relative economic weight of the two regions and $z_{i}$ is their relative political weight. Since it is possible that the newer members receive a larger political weight in the ECB council than they have in economic terms, $\mathrm{z}_{2}>\mathrm{s}_{2}$, I allow political and economic weights to differ. In fact, if the present "one country, one vote” principle is extended to the new members they would be significantly over-represented politically (Berger 2002). Even if the proposed changes to the voting structure ECB are implemented (see Ullrich 2004), which would lead to some reduction in the political power of the smaller members, they will continue to have more political than economic weight. But even if the ECB monetary policy would be completely centralized, a political weight of zero would not imply an economic weight of zero. Even if new members do not have a say in the monetary policy, developments in those regions will be taken into account with the relative weight $\mathrm{s}_{2} \cdot{ }^{10}$

The objective function of the larger central bank is therefore

\footnotetext{
${ }^{9}$ Fatum (2006) instead argues that any ECB council is likely to adopt the preferred position of the most conservative member and will thus reflect the Bundesbank's preferred policy.

${ }^{10}$ The assumption is hence that the ECB council members have a European and not national perspective. For other assumptions, see Berger (2006) or Meade and Sheets (2002).
} 


$$
\mathrm{V}^{\mathrm{MU}}=\left(\pi^{\mathrm{MU}}\right)^{2}+\lambda^{\mathrm{MU}}\left(\mathrm{y}^{\mathrm{MU}}\right)^{2}
$$

where $\pi^{\mathrm{MU}}=\mathrm{s}_{1} \pi_{1}+\mathrm{s}_{2} \pi_{2}, \lambda^{\mathrm{MU}}=\mathrm{z}_{1} \lambda_{1}+\mathrm{z}_{2} \lambda_{2}$ and $\mathrm{y}^{\mathrm{MU}}=\mathrm{s}_{1} \mathrm{y}_{1}+\mathrm{s}_{2} \mathrm{y}_{2}$.

The ECB's policy follows from optimizing (9) as

$$
\pi=\hat{\theta}\left(\pi^{\mathrm{e}}+\mathrm{s}_{1} \tau_{1}+\mathrm{s}_{2} \tau_{2}+\mathrm{s}_{1} \gamma_{1} \varepsilon_{1}+\mathrm{s}_{2} \gamma_{2} \varepsilon_{2}\right)
$$

where $\hat{\theta}=z_{1} \theta_{1}+z_{2} \theta_{2}$ and $E[\hat{\theta}]=\theta$. The rate of inflation is equal in both regions and I hence abstract from asymmetric developments in the rate of inflation due, for instance, to the influence of the Balassa-Samuelson effect. Therefore, expected inflation is also the same in both regions. To keep matters simple, I assume $\operatorname{Cov}\left(\varepsilon_{1}, \varepsilon_{2}\right)=0$ and equal variance of shocks in the two regions of the monetary union.

The common central bank reacts to developments in any single member state according to its economic weight, thus neglecting asymmetric national developments or differences in the transmission of monetary policy (Benigno 2004, Hefeker 2007). Developments in larger countries will hence be taken more into account than developments in smaller countries. This applies to structural distortions, $\tau_{\mathrm{i}}$, as well as to shocks $\varepsilon_{\mathrm{i}}$ and to the economies' flexibility in reaction to shocks $\gamma_{\mathrm{i}}$.

Although there is a now a common central bank, I assume that governments’ policies remain uncoordinated and that the national governments decide about their reform efforts without consulting other governments. This is an adequate assumption for the European Monetary Union as of now, despite some tentative attempts by the Commission to coordinate member states' policies in the framework of the Lisbon objectives and the Broad Economic Policy Guidelines. 
Following the same steps as above, structural distortions and flexibility after reforms are

$$
\tau_{\mathrm{i}}=\phi_{\tau} \cdot \frac{\bar{\tau}_{\mathrm{i}}\left[(1-\theta)\left(\phi_{\tau}+\mathrm{a}_{\mathrm{j}}\right)+\mathrm{s}_{\mathrm{i}}^{2} \Theta\right]-\mathrm{s}_{\mathrm{j}} \mathrm{s}_{\mathrm{i}} \Theta \bar{\tau}_{\mathrm{j}}}{(1-\theta)\left(\phi_{\tau}+\mathrm{a}_{\mathrm{j}}\right)\left(\phi_{\tau}+\mathrm{a}_{\mathrm{i}}\right)+\Theta\left[\mathrm{s}_{\mathrm{i}}^{2}\left(\phi_{\tau}+\mathrm{a}_{\mathrm{j}}\right)+\mathrm{s}_{\mathrm{j}}^{2}\left(\phi_{\tau}+\mathrm{a}_{\mathrm{i}}\right)\right]} \quad \mathrm{i}, \mathrm{j}=1,2, \mathrm{i} \neq \mathrm{j},
$$

$$
\gamma_{\mathrm{i}}=\frac{\phi_{\gamma} \bar{\gamma}_{\mathrm{i}}}{\phi_{\gamma}+\mathrm{b}_{\mathrm{i}} \sigma_{\varepsilon}^{2}} \quad \mathrm{i}, \mathrm{j}=1,2, \mathrm{i} \neq \mathrm{j}
$$

where $a_{i}=\lambda\left(1-s_{i} \theta\right), b_{i}=\lambda\left(1-s_{i} \theta\right)^{2}+s_{i}^{2} \Theta$ and obviously $\lambda\left(1-s_{i} \theta\right)>\lambda(1-\theta)$ for all $s_{i}<1$.

Like in the case of monetary autonomy, flexibility is determined through the initial degree of distortions, the aversion to reforms, the variability of economic shocks and the variability of the central bank's reaction function. As before, it follows that shocks and uncertainty are both reform inducing. Because of the assumption that shocks are uncorrelated, flexibility is only affected by the national degree of distortions and independent of those in the other country.

The case of structural distortions is more complicated. First, structural reforms are strategic substitutes. The higher the initial distortions in the other country, the more incentives there are for the government to lower its own distortions. In order to avoid that the higher distortions in the other country create too much inflation, the domestic government has an incentive to implement more reforms itself. As before, the initial level of structural distortions in the home country, $\bar{\tau}_{\mathrm{i}}$ increases the level of distortions after reforms. Second, the influence of uncertainty is not obvious but it can be shown that $\frac{\partial \tau_{\mathrm{i}}}{\partial \sigma_{\theta}^{2}}<0$. That is, distortions will decrease with monetary uncertainty.

The rate of inflation in EMU follows as 


$$
\begin{aligned}
\pi=\hat{\theta} \cdot \frac{\phi_{\tau}\left[\left(\phi_{\tau}+\mathrm{a}_{1}\right) \mathrm{s}_{1} \bar{\tau}_{1}+\left(\phi_{\tau}+\mathrm{a}_{2}\right) \mathrm{s}_{2} \bar{\tau}_{2}\right]}{(1-\theta)\left(\phi_{\tau}+\mathrm{a}_{1}\right)\left(\phi_{\tau}+\mathrm{a}_{2}\right)+\Theta\left[\mathrm{s}_{1}^{2}\left(\phi_{\tau}+\mathrm{a}_{1}\right)+\mathrm{s}_{2}^{2}\left(\phi_{\tau}+\mathrm{a}_{2}\right)\right]} \\
+\hat{\theta} \cdot\left[\mathrm{s}_{1} \frac{\phi_{\gamma} \bar{\gamma}_{1}}{\phi_{\gamma}+\mathrm{b}_{1} \sigma_{\varepsilon}^{2}} \varepsilon_{1}+\mathrm{s}_{2} \frac{\phi_{\gamma} \bar{\gamma}_{2}}{\phi_{\gamma}+\mathrm{b}_{2} \sigma_{\varepsilon}^{2}} \varepsilon_{2}\right] .
\end{aligned}
$$

It is a function of the relative weights of the two countries and depends on whether their flexibility and structural distortions will increase or decrease (which is considered in the next section). Expected inflation, however, is only a question of initial structural distortions and can thus readily be compared to the expected inflation in each country before monetary union. $\mathrm{E}\left[\pi_{\mathrm{i}}^{\mathrm{N}}\right]>\mathrm{E}\left[\pi^{\mathrm{MU}}\right]$, where the superscripts $\mathrm{N}$ and MU refer to monetary autonomy and monetary union respectively, requires that

$$
\bar{\tau}_{\mathrm{i}}\left(\phi_{\tau}+\lambda\right)\left[(1-\theta)\left(\phi_{\tau}+\mathrm{a}_{\mathrm{j}}\right)+\Theta\left(\mathrm{s}_{\mathrm{j}}-\mathrm{s}_{\mathrm{i}}\right)\right]>\bar{\tau}_{\mathrm{j}}\left[(1-\theta)\left(\phi_{\tau}+\lambda(1-\theta)\right)+\Theta\right]\left(\phi_{\tau}+\mathrm{a}_{\mathrm{i}}\right)
$$

Thus, a single country can expect a fall in the rate of inflation if it enters a monetary union with a country that is sufficiently less distorted than the country itself. In this case, monetary discipline is imported because the lower distortions in that country lead the common central bank to run a less inflationary policy than the national central bank did because of these structural distortions. The positive effect of reducing inflation is increasing in the relative economic size of the less distorted country $s_{j}>s_{i}$.

\section{The Influence of Monetary Union on Reforms}

As I have argued above, the case of uncertainty is most relevant for the monetary union because in the initial years after enlargement, a larger policy making organ is likely to create 
more uncertainty. I will hence assume that uncertainty under national autonomy is zero $\gamma_{i}^{N} \mid \sigma_{\theta}^{2}=0$ whereas it is positive in the monetary union $\gamma_{i}^{\mathrm{MU}} \mid \sigma_{\theta}^{2}>0$.

From (5) and (12), the condition that EMU leads to more flexibility, $\gamma_{i}^{\mathrm{N}}>\gamma_{\mathrm{i}}^{\mathrm{MU}}$, is

$$
\mathrm{s}_{\mathrm{i}}^{2}\left(\theta^{2}+\sigma_{\theta}^{2}\right)>\theta^{2}\left(\mathrm{~s}_{\mathrm{i}}-\mathrm{s}_{\mathrm{j}}\right),
$$

and it is always fulfilled. Even if setting $\sigma_{\theta}^{2}=0$ the condition simplifies to $\theta^{2} s_{j}\left(1-s_{i}\right)>0$ by making use of the fact that $s_{i}+s_{j}=1$. Naturally, only if $s_{i}=1$ it follows that $\gamma_{i}^{N}=\gamma_{i}^{M U}$.

The creation of a monetary union leads countries to implement measures to become more flexible and increase their ability to cope with economic shocks. This incentive is increased if monetary union leads to more uncertainty concerning the reaction of the common central bank. However, even if this is not the case, countries have an incentive to become more flexible because they realize the common central bank will care less for idiosyncratic shocks that hit single countries. Therefore, the only alternative instrument to cope with such shocks is to make the economy more flexible and less vulnerable to such shocks. Monetary union serves as an engine for more reforms.

Next, I compare the levels of structural distortion under monetary union $\tau_{\mathrm{i}}^{\mathrm{MU}} \mid \sigma_{\theta}^{2}>0$ and under monetary autonomy $\tau_{\mathrm{i}}^{\mathrm{N}} \mid \sigma_{\theta}^{2}=0$. From (7) and (11), one finds that EMU leads to a reduction in structural distortions, $\tau_{\mathrm{i}}^{\mathrm{N}}>\tau_{\mathrm{i}}^{\mathrm{MU}}$, if

$$
\begin{aligned}
\theta^{2} \mathrm{~s}_{\mathrm{i}} \mathrm{s}_{\mathrm{j}}\left[(1-\theta)\left(\phi_{\tau}+\lambda(1-\theta)\right)\left(\bar{\tau}_{\mathrm{j}}-\bar{\tau}_{\mathrm{i}}\right)+\theta^{2}\left(\bar{\tau}_{\mathrm{j}}-\mathrm{s}_{\mathrm{i}} \bar{\tau}_{\mathrm{i}}\right)\right] \\
+(1+\lambda) \sigma_{\theta}^{2}\left[\mathrm{~s}_{\mathrm{i}}(1-\theta)\left(\phi_{\tau}+\mathrm{a}_{\mathrm{j}}\right)\left(\mathrm{s}_{\mathrm{i}} \bar{\tau}_{\mathrm{i}}+\mathrm{s}_{\mathrm{j}} \bar{\tau}_{\mathrm{j}}\right)+\mathrm{s}_{\mathrm{i}} \mathrm{s}_{\mathrm{j}} \theta^{2}\left(\bar{\tau}_{\mathrm{j}}-\mathrm{s}_{\mathrm{i}} \bar{\tau}_{\mathrm{i}}\right)\right]>0 .
\end{aligned}
$$


I analyze the condition in parts. For the case without uncertainty (so that $\sigma_{\theta}^{2}=0$ ) it is possible to show the condition is only fulfilled if $\bar{\tau}_{\mathrm{j}}>\bar{\tau}_{\mathrm{i}}$. That is, countries will reduce their distortions if they lower distortions than their partners in the monetary union while countries that are more distorted experience a further deterioration of their structural distortions. Hence, some countries will experience an increase in structural distortions while others see their distortions fall. Since the second part of the condition (multiplied by $\sigma_{\theta}^{2}$ ) is always positive it follows that uncertainty can, at least partially, compensate for the negative effect of $\bar{\tau}_{\mathrm{j}}<\bar{\tau}_{\mathrm{i}}$. A high enough degree of uncertainty is an incentive for all countries to implement more structural reforms, even for those that would not implement them without uncertainty.

The intuition of the result is straightforward. As has been shown in the earlier literature, for instance by Calmfors (2001) and Sibert and Sutherland (2000), if structural reforms and monetary policy are considered as substitutes by the government, and if the government is a Stackelberg leader with respect to the central bank, governments implement structural reforms to reduce inflationary pressure that arises because the central bank uses monetary policy to lower structural unemployment (which is, of course, in vain-reflecting the standard inflation bias (Barro and Gordon 1983)). Because a monetary union implies that the central bank will no longer react as strongly to distortions in the home country as the national central bank before monetary union, inflationary pressure automatically declines and this prompts the reform-averse government to reduce its reform efforts.

Hefeker (2005) has demonstrated that this result can be turned around if the assumption of symmetric countries is given up. Countries that are more distorted will reduce their reform efforts, as demonstrated in the earlier literature, but the less distorted countries fear the “import” of inflation and are more concerned to reduce this pressure by implementing even more reforms. Hence, asymmetric monetary unions are likely to see a further polarization of structural unemployment in the monetary union. 
This negative consequence for some of the members of the larger EMU, however, can be avoided if the common central bank is less open and transparent than national central banks. By deliberately creating uncertainty about its reaction function, structural distortions can be reduced even in countries that are relatively more distorted. While it certainly not easy to deliberately create uncertainty, the conclusion at least is that maximum transparency in the larger central bank could have negative effects for those member countries that enter monetary union relatively more distorted.

\section{Conclusion}

The paper has demonstrated the beneficial, that is, reform inducing effects of uncertainty about the central bank's reaction function. While this does not invalidate the general positive effects of central bank transparency, clear policy decision and communication about them, the paper stresses that there can also be positive effects of preference uncertainty. In a closed economy, uncertainty leads governments to implement more structural reforms and to try to make the economy less vulnerable to economic shocks.

In the case of monetary union, it follows that all governments have an incentive to make their economies more flexible in order to be able to compensate for less stabilizing influence of the central bank. Since the central bank will react the least to the smallest economies their incentives to become more flexible in a monetary union are largest. This would predict that the new member states of the EMU will be more flexible in the monetary union than the larger (and older) member states. This might be one possible explanation (among others) why in general smaller economies are more flexible than larger ones, and why the difference in these matters between larger and smaller economies has further increased since the start of EMU. 
The probability that monetary union will also lead to a reduction in structural distortions in member countries is less uniform. Only those countries that have relatively low distortions will reduce their distortions further, whereas those that have levels of distortions are likely to undertake less efforts to lower them. Monetary union, according to this model, will hence lead to a further polarization of high and low distortion countries. However, the uncertainty created by the introduction (or extension) of monetary union can potentially counteract this negative influence for high distortion countries.

This has also implications for the relative weights that countries should have in a monetary union. If increasing the relative weight of newcomers will lead to more uncertainty about the reaction of the central bank than this is something that should not necessarily be avoided. There is hence some justification for the "one country, one vote" principle that the ECB applies to its decision making structure. A full centralization, as has been advocated by some observers, could be less beneficial than is often claimed even if leading to more efficient decision making. If having more members in the decision making process increases uncertainty, this ambiguity need not only have negative consequences. Deriving the optimal amount of uncertainty, however, would require having a fuller model that also incorporates the positive effects of lower uncertainty and transparency.

\section{References}

Baldwin, Richard, Erik Berglöf, Francesco Giavazzi and Mika Widgrén (2000) EU Reforms for Tomorrow’s Europe, CEPR-Discussion Paper 2623.

Barro, Robert and David Gordon (1983) A Positive Theory of Monetary Policy in a Natural Rate Model, Journal of Political Economy 91, 589-610.

Benigno, Pierpaolo (2004) Optimal Monetary Policy in a Currency Area, Journal of International Economics 63, 293-320.

Berger, Helge (2002) The ECB and Euro-Area Enlargement, IMF-Working Paper 02/175.

Berger, Helge and Stephan Danninger (2005) Labor and Product Market Deregulation: Partial, Sequential, or Simultaneous Reform?, IMF-Working Paper 05/227. 
Brainard, William (1967) Uncertainty and the Effectiveness of Policy, American Economic Review 57, 411-425.

Calmfors, Lars (2001) Labor Market Reform and Monetary Union, Journal of Labor Economics 19, 265-289.

Canzoneri, Matthew (1985) Monetary Policy Games and the Role of Private Information, American Economic Review 75, 1056-1070.

Carpenter, Seth (2004) Transparency and Monetary Policy: What Does the Academic Literature Tell Policymakers?, Board of Governors of the Federal Reserve System, mimeo.

Cukierman, Alex and Alan Meltzer (1986) A Theory of Ambiguity, Credibility and Independence under Discretion and Asymmetric Information, Econometrica 54, 10991128.

Eijffinger, Sylvester and Marco Hoeberichts (2000) Central Bank Accountability and Transparency: Theory and Some Evidence, Bundesbank Discussion Paper 06/00.

Fatum, Rasmus (2006) One Monetary Policy and 18 Central Bankers: The European Monetary Policy as a Game of Strategic Delegation, Journal of Monetary Economics 53, 659-669.

Faust, Jon and Lars Svensson (2001) Transparency and Credibility: Monetary Policy with Unobservable Goals, International Economic Review 42, 369-397.

Faust, Jon and Lars Svensson (2002) The Equilibrium Degree of Transparency and Control in Monetary Policy, Journal of Money, Credit and Banking 34, 520-539.

Geraats, Petra (2002) Central Bank Transparency, Economic Journal 112, F 532-565.

Gerling, Kerstin, Hans Peter Grüner, Alexandra Kiel and Elisabeth Schulte (2005) Information Acquisition and Decision Making in Committees: A Survey, European Journal of Political Economy 21, 563-597.

Goldberg, Linda and Michael Klein (2005) Establishing Credibility: Evolving Perceptions of the European Central Bank, NBER Working Paper 11792.

Grüner, Hans Peter (2002) How Much Should Central Banks Talk? A New Argument, Economics Letters 77, 195-198.

Hefeker, Carsten (2003) Federal Monetary Policy, Scandinavian Journal of Economics 105, 643-659.

Hefeker, Carsten (2005) Structural Reforms and the Enlargement of Monetary Union, in P. de Grauwe and J. Mélitz, eds. Prospects for Monetary Union after the Euro, Cambridge: MIT-Press, 31-53.

Hughes Hallett, Andrew and Jan Libich (2006) Central Bank Independence, Accountability and Transparency: Complements or Strategic Substitutes?, CEPR Discussion Paper 5470 . 
Jensen, Henrik (2002) Optimal Degree of Transparency in Monetary Policymaking, Scandinavian Journal of Economics 104, 399-422.

Meade, Ellen and Nathan Sheets (2002) Regional Influences on U.S. Monetary Policy: Some Implications for Europe, Board of Governors of the Federal Reserve System, International Finance Discussion Paper 721.

Sibert, Anne and Alan Sutherland (2000) Monetary Regimes and Labour Market Reform, Journal of International Economics 51, 421-435.

Söderström, Ulf (2002) Monetary Policy with Uncertain Parameters, Scandinavian Journal of Economics 104, 125-145.

Sorensen, Jan Rose (1991) Political Uncertainty and Macroeconomic Performance, Economics Letters 37, 377-381.

Ullrich, Katrin (2004) Decision Making of the ECB: Reform and Voting Power, ZEWDiscussion Paper 04-70.

Van der Cruijsen, Carin and Maria Demertzis (2005) The Impact of Central Bank Transparency on Inflation Expectations, De Nederlandsche Bank, mimeo.

Winkler, Bernhard (2000) Which Kind of Transparency: On the Need for Clarity in Monetary Policy Making, ECB Working Paper 26. 